\title{
Probabilistic fatigue analysis of shop and field treated tubular truss bridges
}

\author{
Scott Walbridge ${ }^{\mathrm{a}, *}$, Alain Nussbaumer ${ }^{\mathrm{b}}$ \\ ${ }^{a}$ Department of Civil and Environmental Engineering, University of Waterloo, 200 University Avenue West, Waterloo, Ontario, Canada, N2L 3G1 \\ ${ }^{\mathrm{b}}$ Swiss Federal Institute of Technology (EPFL), Steel Structures Laboratory (ICOM), Building GC B3 - Office 505, Station 18, Lausanne, CH - 1015, Switzerland
}

Received 2 January 2007; accepted 8 June 2007

\begin{abstract}
This article examines the extent to which post-weld treatment by needle peening can improve the fatigue performance of tubular truss bridges. To do this, the various potential crack sites on several variants of a typical bridge are analyzed using a probabilistic, fracture mechanics-based model. Systems reliability theory is then used to determine the reliability of the entire untreated or treated bridge. The results of this work show that: considering phase effects may result in large reductions in the design stress ranges for these structures, a significant increase in the treatment benefit can be achieved if the treatment is applied after the dead load stresses are introduced, and weld root cracking does not appear to be the critical failure mode for these structures, so long as a strategy of partial treatment is employed.
\end{abstract}

(c) 2007 Elsevier Ltd. All rights reserved.

Keywords: Tubular truss bridges; Fatigue; Post-weld treatment; Needle peening; Probabilistic fracture mechanics

\section{Introduction}

Bridges consisting of steel tubes welded together to form truss girders have seen increasing popularity in recent years $[1-3]$. This trend can be explained by the aesthetic merit of these structures and by recent improvements in the cutting and fabrication techniques for tubular structures [4]. Recent research has been conducted to improve our understanding of the fatigue behaviour of tubular bridge joints in view of the significant differences in loading, scale, and geometry that exist between these joints and the more widely studied tubular joints common to offshore applications [4]. With this improved understanding, the search can now begin for ways of improving the fatigue performance of tubular bridge joints, in view of the significant negative impact that this performance is known to have on the economic viability of these structures.

Two ways of improving the fatigue performance of tubular truss bridges have been considered in recent studies: replacing the directly welded joints with cast steel nodes $[5,6]$, and improving the performance of the fatigue-critical welds by post-weld treatment. In order to investigate the latter possibility, large-scale tests have been carried out, which

\footnotetext{
* Corresponding author. Tel.: +1 519888 4567x38066; fax: +1 5198884349 .

E-mail address: swalbrid@civmail.uwaterloo.ca (S. Walbridge).
}

have demonstrated the potential of post-weld treatment by needle peening for this purpose [4]. Although encouraging, several concerns with the use of residual stress-based treatment methods such as needle, hammer, and ultrasonic peening, have limited the extent to which such findings can be translated into practical guidelines. Firstly, concerns exist about the reliability of these methods, in particular under realistic, variable amplitude loading conditions [7]. Secondly, in the large-scale tests reported in [4], it was seen that the benefit of concentrated treatment of the critical crack site, although substantial, was eventually limited by cracking at a less critical, untreated location. In view of these concerns, an analytical study was subsequently initiated to examine the treatment of tubular truss bridges using a probabilistic approach that would consider the actual variable amplitude loading conditions, as well as the influences of the various potential crack sites or hotspots (untreated or treated) on the overall fatigue reliability of the entire structure $[8,9]$.

Herein, the model developed for this analytical study is briefly described. A tubular truss bridge with typical dimensions and loading conditions is then presented. By analyzing several variants of this bridge using the developed probabilistic model, it was thought that the potential benefit of post-weld treatment for improving tubular bridge fatigue performance could be precisely quantified. Typical results of 

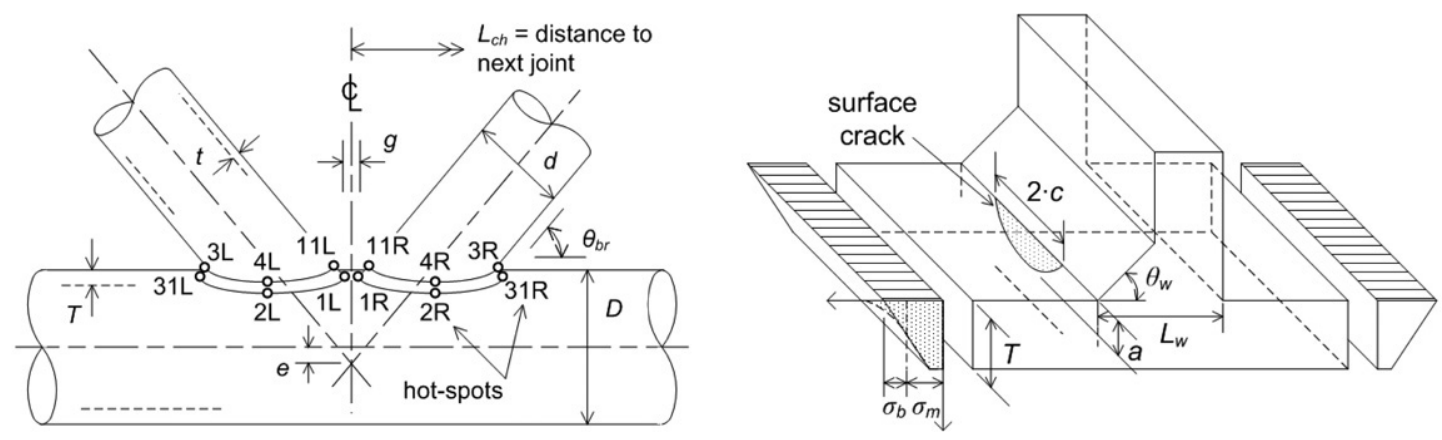

Fig. 1. Tubular $K$-joint and weld toe models.

the analytical study are then presented and used to determine the treatment benefit for the investigated structure. In addition, a number of related issues are discussed herein including: the effect of considering or ignoring phase effects in the codebased fatigue design of tubular truss bridges, the effect of the treatment timing on the treatment benefit (i.e. before or after the introduction of the dead load stresses), and the possibility that post-weld treatment of the fatigue-critical weld toe will simply result in a shift of the eventual crack location to the untreatable weld root. Based on this discussion, a number of areas are highlighted where further study is needed.

The work presented herein focuses on the post-weld treatment by needle peening of tubular truss bridges comprised of CHS members joined by welded, gapped single $K$-joints (see Fig. 1). However, it is believed that the employed models are suitable for the fatigue analysis of tubular structures treated using any of the above-mentioned residual stress-based postweld treatment methods.

\section{Probabilistic model overview}

\subsection{Modelling single potential crack sites}

The probabilistic model employed in the analytical study presented herein is based on a previously developed deterministic linear elastic fracture mechanics (LEFM) model [10], modified for the analysis of gapped single circular hollow section (CHS) $K$-joints (see Fig. 1). The modified model employs a number of design aids developed by others to determine the applied stress intensity factor (SIF) ranges at different crack depths for weld toe cracks at the various potential crack sites or hot-spots on such joints.

The limit state function, $G(\mathbf{z})$, employed in the probabilistic model is founded on the Paris-Erdogan crack growth law, modified to consider crack closure effects and a threshold SIF range, $\Delta K_{\mathrm{th}}$, and integrated over the crack depth range, $a_{0}$ to $a_{c}$. Specifically:

$G(\mathbf{z})=N_{c}-N=\int_{a_{0}}^{a_{c}} \frac{\mathrm{d} a}{C \cdot\left(\Delta K_{\mathrm{eff}}^{m}-\Delta K_{\mathrm{th}}^{m}\right)}-N$

In this expression, $N$ is the actual number of stress cycles and $N_{c}$ is the number of cycles to failure. In order to conduct analyses under variable amplitude loading conditions,
Table 1

Statistical variables used in probabilistic analysis

\begin{tabular}{|c|c|c|c|c|}
\hline Variable & $\mu_{x}$ & $\sigma_{x}$ & Dist. & Units \\
\hline$a_{0}$ & 0.2 & 0.045 & $\mathrm{LN}$ & $\mathrm{mm}$ \\
\hline$(a / c)_{0}$ & 0.5 & 0.16 & $\mathrm{LN}$ & - \\
\hline $\mathrm{VAR}_{\text {traffic }}$ & 1.0 & 0.15 & $\mathrm{~N}$ & - \\
\hline $\mathrm{VAR}_{\text {dead }}$ & 1.0 & 0.10 & $\mathrm{~N}$ & - \\
\hline VAR $_{\mathrm{DOB}}$ & 1.0 & 0.08 & $\mathrm{~N}$ & - \\
\hline $\mathrm{VAR}_{\mathrm{SCF}}$ & 1.0 & 0.04 & $\mathrm{LN}$ & - \\
\hline $\operatorname{VAR}_{M k}$ & 1.0 & 0.05 & $\mathrm{LN}$ & - \\
\hline $\operatorname{VAR}_{L w}$ & 1.0 & 0.10 & $\mathrm{~N}$ & - \\
\hline $\operatorname{VAR}_{\theta w}$ & 1.0 & 0.10 & $\mathrm{~N}$ & - \\
\hline VAR $_{\text {weld }}$ & 1.0 & 0.25 & $\mathrm{~N}$ & - \\
\hline VAR $_{\text {pwt }}$ & 0.5 & 0.10 & $\mathrm{~N}$ & - \\
\hline $\mathrm{LN}(C)$ & -28.80 & 0.55 & $\mathrm{~N}$ & $\mathrm{LN}\left((\mathrm{mm} /\right.$ cycle $\left.) \cdot\left(\mathrm{N} / \mathrm{mm}^{-3 / 2}\right)^{m}\right)$ \\
\hline$\Delta K_{\mathrm{th}}$ & 100.0 & 15.0 & $\mathrm{LN}$ & $\mathrm{MPa} \sqrt{ } \mathrm{mm}$ \\
\hline$a_{c}$ & $0.5 \cdot T$ & - & Det. & $\mathrm{mm}$ \\
\hline$f_{y}$ & 355 & - & Det. & $\mathrm{MPa}$ \\
\hline$m$ & 3.0 & - & Det. & - \\
\hline
\end{tabular}

an equivalent block loading approach is employed (see, for example: [11]). This approach was found to be superior to using an equivalent constant amplitude stress range, in particular for the analysis of the treated crack sites, as discussed in [8].

In Eq. (1) the effective SIF range, $\Delta K_{\text {eff }}$, is taken as:

$$
\begin{aligned}
\Delta K_{\mathrm{eff}}= & \operatorname{MAX}\left(K_{\mathrm{app}, \max }-K_{\mathrm{op}}, 0\right) \\
& -\operatorname{MAX}\left(K_{\mathrm{app}, \min }-K_{\mathrm{op}}, 0\right)
\end{aligned}
$$

where $K_{\text {app, max }}$ and $K_{\text {app,min }}$ are the maximum and minimum SIFs due to the applied load and $K_{\text {op }}$ is the applied SIF at which the crack tip opens upon loading. Specifically:

$K_{\mathrm{op}}=-\left(K_{\mathrm{res}}+K_{\mathrm{pl}}\right)$

where $K_{\text {res }}$ is the SIF due to the residual stresses along the crack path and $K_{\mathrm{pl}}$ is the crack closure SIF. The uncertainties in the input parameters discussed above are considered by treating these parameters as statistical variables (see Table 1). Of particular interest in this study, the uncertainties in the residual stress distributions due to the welding and treatment processes, $\sigma_{\text {weld }}(b)$ and $\sigma_{\text {pwt }}(b)$, are considered using two variables, $\mathrm{VAR}_{\text {weld }}$ and $\mathrm{VAR}_{\text {pwt }}$ (see Fig. 2), which are assigned attributes based on measurements reported in $[10,12,13]$. Using these variables, the assumed residual stress distribution due to 

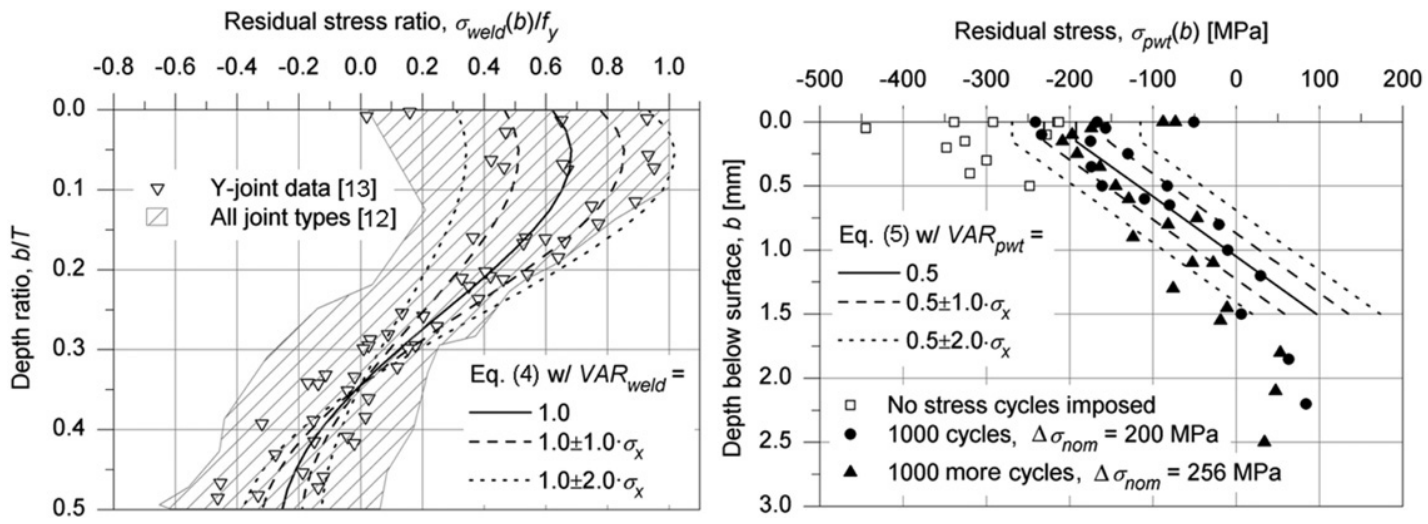

Fig. 2. Residual stresses due to welding (left) and post-weld treatment (right).

the welding process is:

$$
\begin{aligned}
\sigma_{\text {weld }}(b)= & f_{y} \cdot\left(0.62+2.33 \cdot(b / T)-24.13 \cdot(b / T)^{2}\right. \\
& \left.+42.49 \cdot(b / T)^{3}-21.09 \cdot(b / T)^{4}\right) \cdot \text { VAR }_{\text {weld }}
\end{aligned}
$$

where $b$ is the depth below the surface, $T$ is the wall thickness of the cracked member ( $t$ or $T$ in Fig. 1), and $f_{y}$ is the yield strength. This is essentially the empirical expression proposed in [12], shifted to represent an average of the measured data, rather than an upper bound, for the case of $\mathrm{VAR}_{\text {weld }}=1.0[8$, 9]. The assumed post-weld treatment stress distribution is:

$$
\begin{aligned}
\sigma_{\mathrm{pwt}}(b)= & -f_{y} \cdot\left(\mathrm{VAR}_{\mathrm{pwt}}\right) \quad \text { if } b \leq 0.1 \cdot d_{p} \\
= & f_{y} \cdot\left(\left(b / d_{p}\right) \cdot(5 / 6)-\left(1 / 12+\mathrm{VAR}_{\mathrm{pwt}}\right)\right) \\
& \text { if } b>0.1 \cdot d_{p}
\end{aligned}
$$

where $d_{p}$ is the imprint diameter of the peening tool $(1.5 \mathrm{~mm}$ for needle peening). $K_{\text {res }}$ is calculated for each crack depth increment using the approach proposed by [14].

To solve Eq. (2), $K_{\text {app }}$ is determined using the following expression from [15]:

$$
\begin{aligned}
K_{\mathrm{app}}= & \left(M k_{m} \cdot Y_{m} \cdot(1-\mathrm{DOB})+M k_{b} \cdot Y_{b} \cdot \mathrm{DOB}\right) \\
& \cdot \sigma_{\mathrm{hs}, \mathrm{app}} \cdot \sqrt{\pi \cdot a}
\end{aligned}
$$

where $\sigma_{\text {hs,app }}$ is the applied hot-spot stress, $M k_{m}, M k_{b}$, $Y_{m}$, and $Y_{b}$ are the magnification and correction factors for the bending $\left(\sigma_{b}\right)$ and membrane $\left(\sigma_{m}\right)$ stress cases, and $D O B$ is the degree of bending $\left(=\sigma_{b} /\left(\sigma_{b}+\right.\right.$ $\left.\sigma_{m}\right)$, see Fig. 1). $M k_{m}, M k_{b}, Y_{m}, Y_{b}$, and $D O B$ are determined using closed-form equations from [15-17]. $\sigma_{\mathrm{hs}, \text { app }}$ can be calculated for a given peak in the stress history, given the mean applied hot-spot stress level and the hot-spot stress range. The former is determined by adding the hot-spot stress due to the dead load and the mean hot-spot stress due to the traffic load. The latter is simply taken as the hot-spot stress range due to the traffic load. The uncertainty in the dead load hot-spot stress is considered by multiplying this stress by the statistical variable VAR $_{\text {dead. }}$. Uncertainty in the traffic loading is considered through the statistical variable $\mathrm{VAR}_{\text {traffic }}$, by which the hot-spot stress due to the traffic load is multiplied.
The $\mathrm{VAR}_{\text {traffic }}$ variable takes into account uncertainties in the true truck weight distribution, as well as the true traffic volume. Further information regarding the loading model and statistical parameters can be found in [8].

In order to solve the limit state function in Eq. (1), Monte Carlo Simulation [18] is employed, with a crude importance sampling scheme used to reduce the number of trials necessary. Several studies conducted to validate the model described above are presented in $[8,9]$.

\subsection{Modelling structures with multiple potential crack sites}

In order to determine the probabilities of failure of structures comprised of tubular $K$-joints with multiple potential crack sites, lower and upper bound series system reliability models are employed. Specifically, it is first assumed that each $K$-joint in the structure can be modelled as a series system with 16 elements, corresponding with each of the hot-spots identified in Fig. 1 (note: Hot-spots $2 L, 4 L, 2 R$, and $4 R$ each occur twice.). The lower bound model assumes that the failure events associated with the individual hot-spots are fully independent. The probability of failure of the joint can thus be written as follows [18]:

$$
p_{f, \text { joint }}=1-\left(1-p_{f, 1 L}\right) \cdot\left(1-p_{f, 11 L}\right) \cdots\left(1-p_{f, 4 R}\right)
$$

where $p_{f, \text { joint }}$ is the probability of joint failure; $p_{f, 1 L}$ is the probability of failure of Site $1 L$, etc. (recall that the reliability index, $\left.\beta=-\Phi^{-1}\left(p_{f}\right)\right)$. The upper bound reliability model assumes full correlation of the failure events associated with each potential crack site, and takes the following form [18]:

$p_{f, \text { joint }}=\operatorname{MAX}\left(p_{f, 1 L}, p_{f, 11 L}, \ldots, p_{f, 4 R}\right)$

To determine the probabilities of failure of structures with multiple joints, a similar approach is employed. Note that the lower and upper bound reliability models provide upper and lower bound predictions of the probability of failure respectively (since $\beta$ increases as $p_{f}$ decreases).

\section{Description of investigated bridge structure}

Using the probabilistic approach described above, studies were carried out on a typical, full-scale steel-concrete 
Elevation:

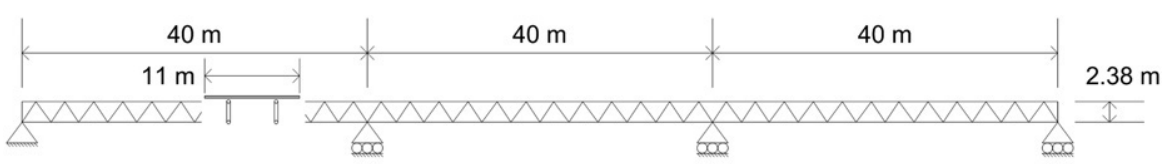

Interior span:
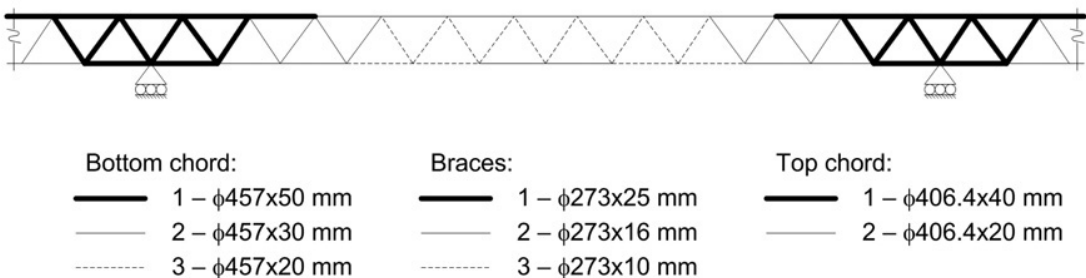

Fig. 3. Investigated bridge geometry and Bridge I member sizes.

composite tubular truss bridge under realistic, variable amplitude loading conditions. The geometry of the studied bridge structure is presented in Fig. 3. A variant of this bridge (Bridge I) was first designed to meet the static strength and serviceability requirements of the Swiss Design Codes (SIA 2003) [19]. These codes follow in general the principles of the Eurocode for structures (Eurocode 2002) [20].

The resulting member sizes are presented in Fig. 3. For this design, the slab was assumed to be $300 \mathrm{~mm}$ thick over each truss, thinning to $250 \mathrm{~mm}$ at the edges and centre of the deck. Reinforcement ratios of $1 \%$ and $1.5 \%$ were assumed at the mid-span and over the supports respectively. A modulus of elasticity ratio ( $\left.E_{\text {steel }} / E_{\text {concrete }}\right)$ of 10 was assumed. The slab was assumed to be cracked over the supports, meaning that only the reinforcement was assumed to contribute to the top chord stiffness in these areas.

A second bridge variant (Bridge $\mathrm{V}$ ) was then designed for fatigue, based on a deterministic, code-based fatigue verification also carried out in accordance with the requirements of [19], including the following assumptions: a planned service life of 70 years, a 40 tonne legal truck weight limit, and Principal Road traffic, i.e. a traffic volume of $5 \times 10^{5}$ trucks/dir./year (bidirectional traffic was assumed).

The design truck used in the (SIA 2003) [19] fatigue verification consists of two $270 \mathrm{kN}$ axle loads spaced $1.2 \mathrm{~m}$ apart. The verification consists of evaluating the following relationship:

$\Delta \sigma_{E 2} \leq \frac{\Delta \sigma_{c, t}}{\gamma_{M f}}$

where $\Delta \sigma_{E 2}$ is the equivalent design hot-spot stress range at $2 \times 10^{6}$ cycles, calculated as follows:

$\Delta \sigma_{E 2}=\lambda_{1} \cdot \Delta \sigma\left(Q_{\text {fat }}\right)$

where $\Delta \sigma\left(Q_{\text {fat }}\right)$ can be taken as the hot-spot stress range, $\Delta \sigma_{\mathrm{hs}}$, at the location of interest due to a single passage of the design truck and $\lambda_{1}$ is a damage equivalence factor $\left(\lambda_{1}=1.42\right.$ for a $40 \mathrm{~m}$ bridge span on a Principal Road). In Eq. (9), $\Delta \sigma_{c, t}$ is the fatigue strength corresponding with $2 \times 10^{6}$ applied stress cycles. According to [4], $\Delta \sigma_{c, 20}=86 \mathrm{MPa}$ should be used for the hot-spot stress-based design of tubular bridge joints, with a reference wall thickness of $20 \mathrm{~mm}$. The following size effect correction factor is used:

$\frac{\Delta \sigma_{c, t}}{\Delta \sigma_{c, 20}}=\left(\frac{20}{T \text { or } t}\right)^{0.25}$

In Eq. (9), $\gamma_{M f}$ takes on a value between 1.0 and 1.35 depending on the ease with which fatigue damage may be detected/repaired and the consequence of fatigue failure. For each joint along the bottom chord of the interior span, the deterministic verification was carried out for each of the hotspots in Fig. 1. Under a given set of loads, the stress, $\sigma_{\mathrm{hs}}$, at a given hot-spot can be determined using the following expression:

$$
\begin{aligned}
\sigma_{\mathrm{hs}}= & \sigma_{a x \_b r} \cdot \mathrm{SCF}_{a x \_b r}+\sigma_{a x_{\_} c h} \cdot \mathrm{SCF}_{a x_{-} c h} \\
& +\sigma_{i p b 1 \_b r} \cdot \mathrm{SCF}_{i p b 1 \_b r}+\sigma_{i p b 2 \_b r} \cdot \mathrm{SCF}_{i p b 2 \_b r} \\
& +\sigma_{i p b \_c h} \cdot \mathrm{SCF}_{i p b \_c h}
\end{aligned}
$$

where $\sigma_{a x} b r$ is the nominal member stress due to the balanced axial brace load case; and $\mathrm{SCF}_{a x \_b r}$ is the corresponding stress concentration factor, etc. The five load cases implicated in Eq. (12) are shown in Fig. 4(a). The associated nominal member stresses can be determined by structural analysis. In the current study, the SCFs in Eq. (12) were determined using tables for CHS $K$-joints from [4]. To determine the nominal member stresses, a simplified structural analysis was carried out wherein no interaction or load sharing between the two trusses was considered (i.e. each truss carries one lane of traffic).

At each hot-spot location, the equivalent design hot-spot stress range, $\Delta \sigma_{E 2}$, was first calculated by taking the nominal member stress ranges for each of the five load cases in Fig. 4(a), multiplying them by the appropriate SCFs, and then summing the results to get the total hot-spot stress range, $\Delta \sigma\left(Q_{\text {fat }}\right)$ [21]. In employing this approach, phase effects were conservatively ignored, i.e. it was effectively assumed that the stress peaks for each load case correspond with the same truck position along the bridge length. This assumption is examined in greater detail in Section 5.1. The result of the code-based fatigue design was a significant increase in the steel weight for Bridge $\mathrm{V}$ in 

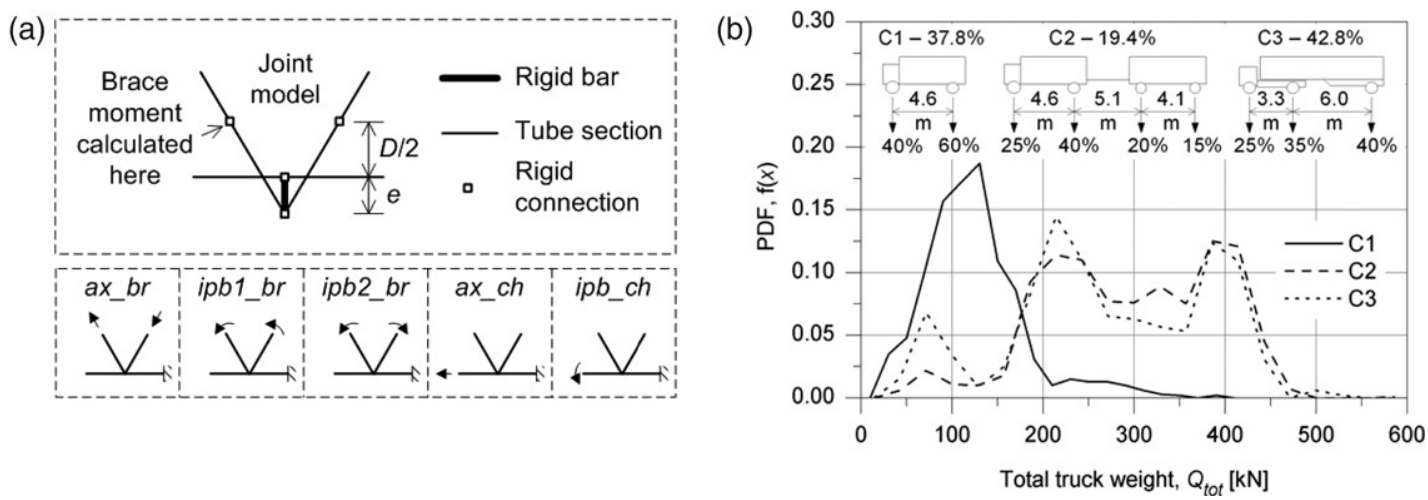

Fig. 4. (a) $K$-joint structural model and nominal joint load cases. (b) Traffic model.

Table 2

Member sizes for five variants of investigated bridge

\begin{tabular}{|c|c|c|c|c|c|c|}
\hline \multirow{2}{*}{$\begin{array}{l}\text { Bridge: } \\
\text { Description: }\end{array}$} & & \multirow{2}{*}{$\begin{array}{l}\text { I } \\
\text { Designed for static strength }\end{array}$} & II & III & IV & \multirow{2}{*}{$\begin{array}{l}\mathrm{V} \\
\text { Designed for fatigue }\end{array}$} \\
\hline & & & \multicolumn{3}{|c|}{ Intermediate designs } & \\
\hline \multirow[t]{3}{*}{ Bottom chord } & 1 & $457 \times 50^{\mathrm{a}}$ & $457 \times 50$ & $457 \times 60$ & $508 \times 70$ & $559 \times 80$ \\
\hline & 2 & $457 \times 30$ & $457 \times 36$ & $457 \times 60$ & $508 \times 70$ & $559 \times 80$ \\
\hline & 3 & $457 \times 20$ & $457 \times 36$ & $457 \times 60$ & $508 \times 70$ & $559 \times 80$ \\
\hline \multirow[t]{3}{*}{ Braces } & 1 & $273 \times 25$ & $273 \times 25$ & $273 \times 30$ & $323.9 \times 35$ & $355.6 \times 40$ \\
\hline & 2 & $273 \times 16$ & $273 \times 16$ & $273 \times 20$ & $323.9 \times 25$ & $355.6 \times 30$ \\
\hline & 3 & $273 \times 10$ & $273 \times 10$ & $273 \times 16$ & $323.9 \times 20$ & $355.6 \times 25$ \\
\hline \multirow[t]{2}{*}{ Top chord } & 1 & $406.4 \times 40$ & $457 \times 50$ & $457 \times 60$ & $508 \times 70$ & $559 \times 80$ \\
\hline & 2 & $406.4 \times 20$ & $457 \times 36$ & $457 \times 60$ & $508 \times 70$ & $559 \times 80$ \\
\hline \multirow[t]{2}{*}{ Steel weight } & $\mathrm{kN} / \mathrm{m}^{\mathrm{b}}$ & 8.8 & 10.9 & 15.4 & 19.7 & 24.3 \\
\hline & $\%^{\mathrm{c}}$ & 11.1 & 13.4 & 17.9 & 21.8 & 25.7 \\
\hline
\end{tabular}

a All tube dimensions in $\mathrm{mm}$.

${ }^{\mathrm{b}}$ One truss, including $20 \%$ of Bridge I steel weight as allowance for supporting structural elements.

c $\%$ of total weight $=($ total steel weight/total bridge weight $) \cdot 100 \%$.

comparison with that of Bridge I. Three intermediate variants (Bridges II-IV) were then conceived with varying degrees of under-design for fatigue. The member sizes and steel weights for each bridge variant are summarized in Table 2 .

\section{Probabilistic analysis of investigated bridge variants}

\subsection{Analysis of untreated and shop treatment cases}

With the resulting five bridge variants it was thought that the potential benefit of treatment could be precisely determined. In order to do this, 72 bottom chord hot-spots on half of the interior span of one truss on each bridge variant were analyzed using the probabilistic model. A traffic model based on weigh scale measurements taken on the main highway between Bern and Zurich [22], modified to consider the new 40 tonne Swiss legal truck weight limit, was used for the analysis of all five variants (see Fig. 4(b)). In applying this model, the indicated truck weights were multiplied by a deterministic dynamic factor of 1.3 .

Initially, each potential crack site was analyzed twiceuntreated and treated. To determine the residual stress distribution, $\sigma_{\text {res }}(b)$, the parameter PWT was introduced, such that:

$$
\begin{aligned}
\sigma_{\text {res }}(b) & =\operatorname{MIN}\left(\sigma_{\text {pwt }}(b), \sigma_{\text {weld }}(b)\right) \quad \text { if PWT }=1 \\
& =\sigma_{\text {weld }}(b) \quad \text { if PWT }=0
\end{aligned}
$$

The stress due to the dead load was then considered in the calculation of $K_{\text {app }}$ (see Eq. (6)). This approach effectively assumes that all of the residual stresses are imposed prior to the application of the dead load, as would normally be the case if the treatment were applied in the shop.

A typical result of the analysis described above is presented in Fig. 5 for Bridge III. In this figure, envelopes of fatigue reliability, $\beta$, versus time are plotted for the untreated and the treated bridge. An important finding presented in [8] was that the same treatment benefit could be obtained using either of the two treatment strategies (TS3 or TS4) shown in this figure, when a needle peening treatment of normal intensity and uniformity (denoted tb2s treatment in [8]) was employed. The envelopes in this figure consider the unknown level of correlation between the fatigue reliabilities of the various potential crack sites in the bridge according to Eqs. (7) and (8). As can be seen in this figure, the effect of the treatment is a significant increase in $\beta$ throughout the planned service life for this bridge variant.

In Fig. 6, curves are presented comparing the fatigue lives, in terms of the number of trucks, $T_{r}$, for each of the untreated (NT) and treated (tb2s) bridge variants as a function of the steel weight. In this figure, the curves for the treated bridge variants were again found to be identical for both for treatment strategies: TS3 and TS4. Separate graphs are presented to 

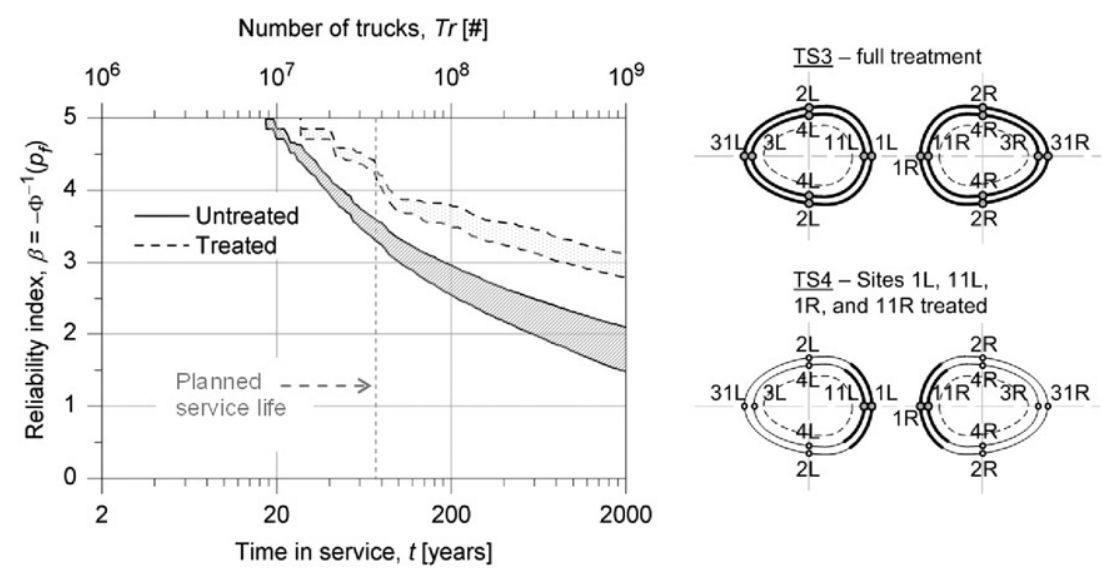

Fig. 5. Fatigue reliability versus time envelopes for Bridge III.
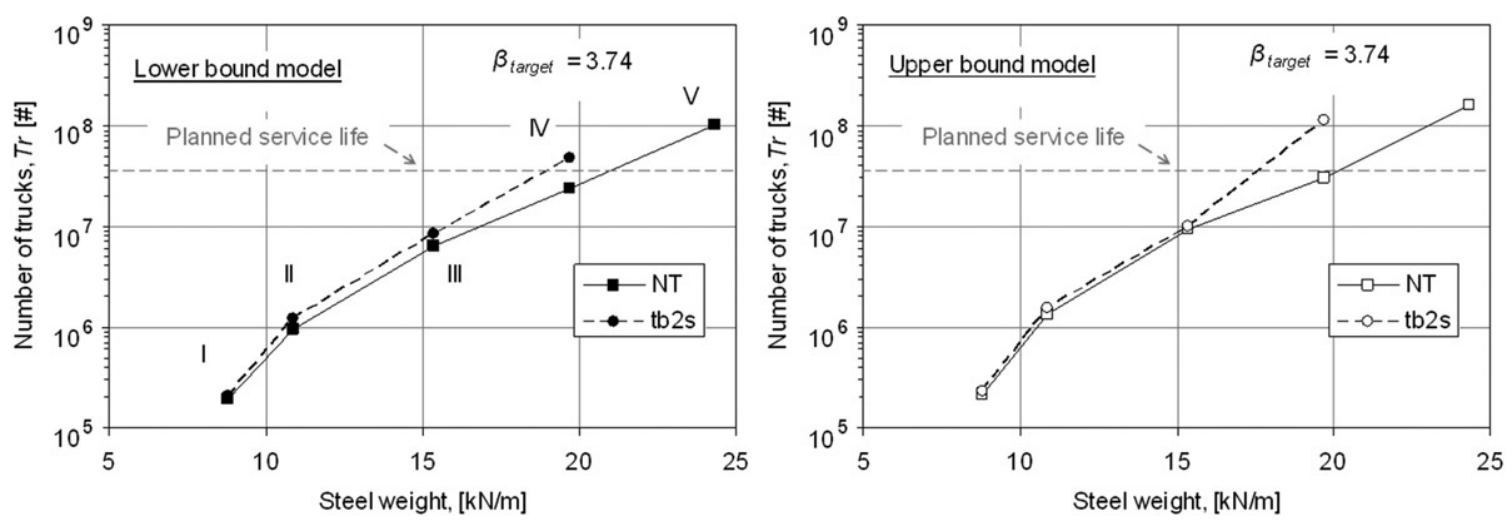

Fig. 6. Fatigue life versus steel weight curves for the investigated bridge.

distinguish the reliability versus steel weight curves obtained using the lower and upper bound series system reliability models. The fatigue lives in Fig. 6 correspond with the time at which $\beta$ drops below a target reliability index, $\beta_{\text {target }}$, of 3.74. [20] suggests a $\beta_{\text {target }}$ range for the fatigue limit state of $\left(1.16 \leq \beta_{\text {target }} \leq 3.74\right)$ for a planned service life of 70 years, again depending essentially on the ease with which fatigue damage can be detected/repaired and the consequence of fatigue failure. This range is used herein to facilitate quantitative comparisons. For example, given an untreated bridge with a planned service life of 70 years, the fatigue life of a treated bridge of equal weight can be estimated using curves such as those in Fig. 6. For the investigated bridge, this was found to result in a fatigue life improvement ranging from $250 \%$ to $320 \%$, for $\beta_{\text {target }}=3.74$, depending on which series system reliability model is used [8]. For $\beta_{\text {target }}=1.16$, the corresponding fatigue life improvement was found to range from $120 \%$ to $930 \%$.

\subsection{Analysis of field treatment case (treatment after introduc- tion of the dead load stresses)}

In studying the fatigue life improvements due to post-weld treatment for the various individual hot-spots in each of the five bridge variants, a strong correlation was observed between the mean applied hot-spot stress level and the calculated treatment benefit. This relationship can be seen in the mean design hot-spot stress, $\sigma_{\text {mean }}$, versus fatigue life improvement, \%imp, data plotted in Fig. 7(a) for $\beta_{\text {target }}=3.74$. The mean hot-spot stress in this figure is taken as the hot-spot stress due to the dead load plus the average of the maximum and minimum hotspot stresses due to a single passage of the (SIA 2003) design truck [19].

In Fig. 7(a), data is presented for the hot-spots with finite untreated and treated fatigue lives only $\left(T_{r}<\sim 2 \times 10^{9}\right.$ trucks) on all five bridge variants. In this figure, results for three different treatment intensities are compared, where treatment intensity is characterized by the mean of the statistical variable $\mathrm{VAR}_{\mathrm{pwt}}$. Examining these results, it can be observed that as the mean hot-spot stress increases, the fatigue life improvement, \%imp, decreases. This parameter increases, however, with an increase in the treatment intensity. Based on the data presented in Fig. 7(a), it can be concluded that for normal intensity treatment $\left(\mu\left(\mathrm{VAR}_{\mathrm{pwt}}\right)=0.50\right)$, a fatigue life improvement, \%imp, of at least $100 \%$ is always achieved, as long as $\sigma_{\text {mean }}$ is less than $\sim 90 \mathrm{MPa}$. A fatigue life improvement, \%imp, of at least $10 \%$ is always achieved, as long as $\sigma_{\text {mean }}$ is less than $\sim 150 \mathrm{MPa}$. In Fig. 7(b), $\sigma_{\text {mean }}$ is non-dimensionalized by the treatment intensity. The resulting narrow band of data forms the basis of a crude empirical model for predicting the treatment benefit presented in [8].

The strong influence of the mean stress on the treatment benefit observed in Fig. 7(a) and (b) led to the suggestion that 
(a)

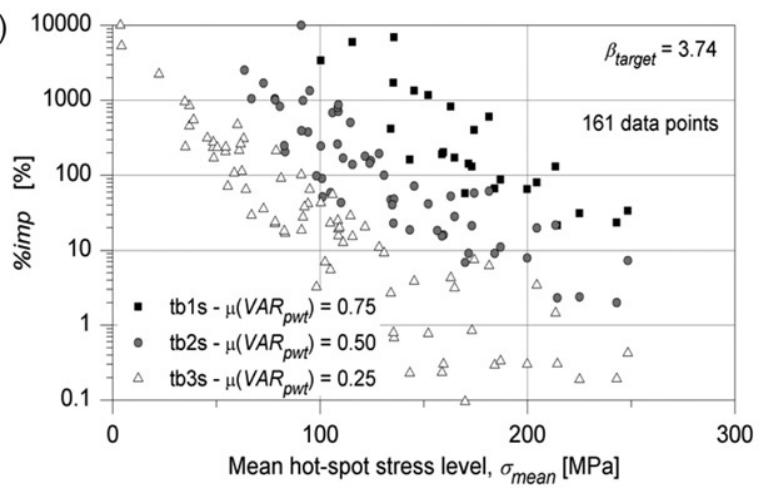

(b)

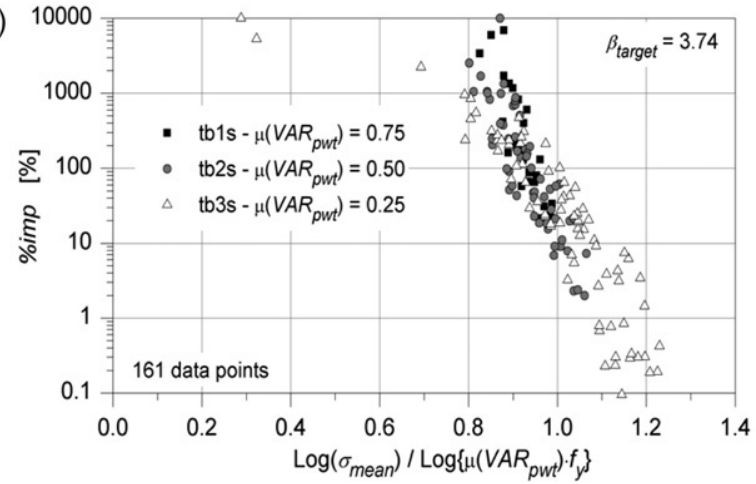

Fig. 7. (a) Fatigue life improvement versus mean stress. (b) Fatigue life improvement versus non-dimensionalized mean stress.

the merits of field treatment be examined. Field treatment, it was thought, could significantly reduce the detrimental effects of high tensile stresses introduced by the dead loads. In [8], a model was proposed for the analysis of potential crack sites wherein the treatment is applied after the introduction of the dead load. The basic assumption of this model is that since the post-weld treatment (i.e. needle peening) works primarily by plastically deforming a thin layer at the surface of the treated detail, it can be assumed that the treatment will essentially negate the tensile dead load stresses over the treatment depth. For the current study, the actual modelling of this phenomenon had to be done indirectly, because the dead load stress distribution is never calculated in applying the analytical model presented in Section 2 (rather the corresponding SIF is determined directly using Eq. (6)).

A very simple approach for circumventing this problem is to assume that the SIF due to the dead load is zero until the crack grows to the depth at which the residual stress due to post-weld treatment crosses the neutral axis. Once the crack grows to this depth, the dead load SIF could simply be turned $o n$. This would result in a crack growth rate slightly higher than the growth rate due to the actual distribution of the combined welding, treatment, and dead load stresses. Since most of the fatigue life occurs at the smaller crack depths, such a model should still model fairly well the case of treatment after dead load application.

In [8], a slightly modified version of this approach was employed wherein at the point when the crack depth reaches the depth at which the dead load SIF is to be turned on, the SIF due to the dead load is calculated. Following this, upon activation of the dead load SIF, an additional uniform stress block is introduced with a depth equal to the crack depth at the transition point and a magnitude such that it results in an SIF at the transition crack depth equal but opposite to that of the dead load. It was expected that this model would give more accurate results than the simpler model described above. In fact, a comparative study found the difference in the results obtained using these two models to be negligible.

In Fig. 8, sample SIF distributions due to the residual stresses and dead load are shown for untreated, shop treated, and field treated potential crack sites. $\mathrm{VAR}_{\text {weld }}=1.0$ and $\mathrm{VAR}_{\text {pwt }}=0.5$ are assumed, and the case of a tensile dead load hot-spot stress and a wall thickness of $T=20 \mathrm{~mm}$ is modelled.
A possible shortcoming of the adopted model, is that it assumes linear elastic material behaviour regardless of the stress level. In reality, cases can be envisioned where combinations of tensile welding and dead load stresses will result in yielding near the surface of the weld toe. It is expected that the effect of ignoring this possibility should be small however, since in this case:

- if the crack site is untreated, then the effective SIF range will typically be equal to the applied SIF range (i.e. the crack will be open for the entire cycle regardless of the mean stress level), and

- if the crack site is treated, then this tensile stress will be negated anyways by the post-weld treatment applied after the dead load stresses are introduced.

The use of the adopted, simplified model was thought necessary to facilitate timely execution of the large numbers of calculations required for the probabilistic analysis of entire tubular bridges. Further study may be warranted, however, to determine the implications (if any) of the adopted linear elastic model.

In order to study the influence of the treatment timing, the hot-spots on all five bridge variants were reanalyzed with the SIFs due to the dead load and treatment stresses superimposed so as to model the second case in Fig. 8 of field treatment. In Fig. 9, the results for this study are plotted for two treatment strategies: NT (not treated) and TS4 (Sites $1 L, 11 L, 1 R$, and $11 R$ treated only_-see Fig. 5). In this figure, 'tb2s' and 'tb2f' refer to normal intensity/uniformity shop and field treatment respectively.

Based on the results presented in Fig. 9, it can be concluded that the treatment benefit is significantly greater when the treatment is applied after the introduction of the dead load stresses. It should be noted that the relative lack of data for the case of $\beta_{\text {target }}=1.16$ is due to the calculation of infinite fatigue lives $\left(T_{r}<\sim 2 \times 10^{9}\right.$ trucks) for relatively light bridge variants when this target index is assumed. The observed improvement in the ability of post-weld treatment methods to increase fatigue life when applied in the field suggests that an interesting domain of application for these methods might be in the rehabilitation or fatigue life extension of existing steel bridges (tubular or conventional).

In Fig. 10, the same data is presented using curves of the reliability index at the planned service life of 70 years versus steel weight. Using curves such as these, the potential savings 


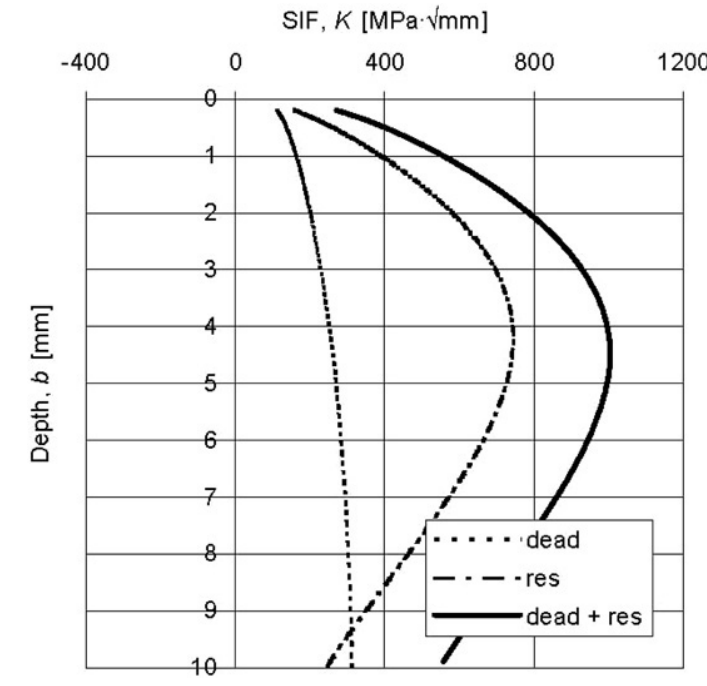

(a) Untreated.

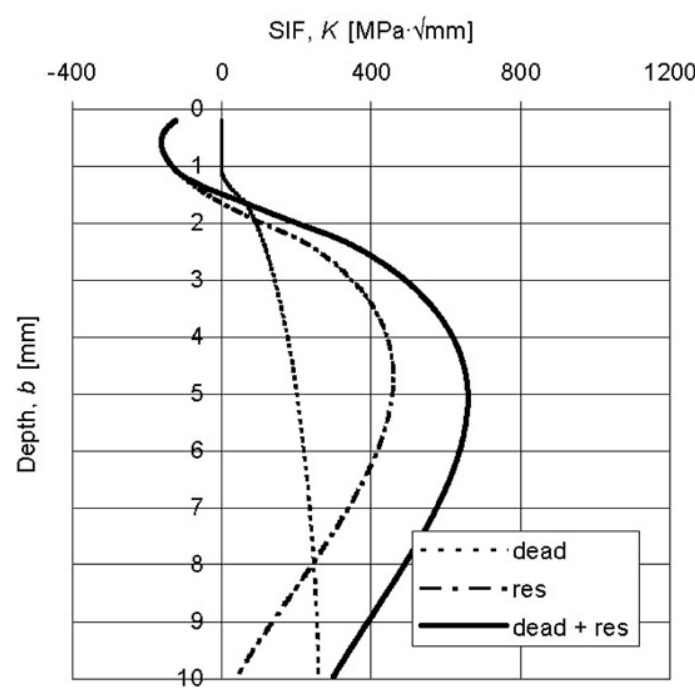

(c) Field treated.

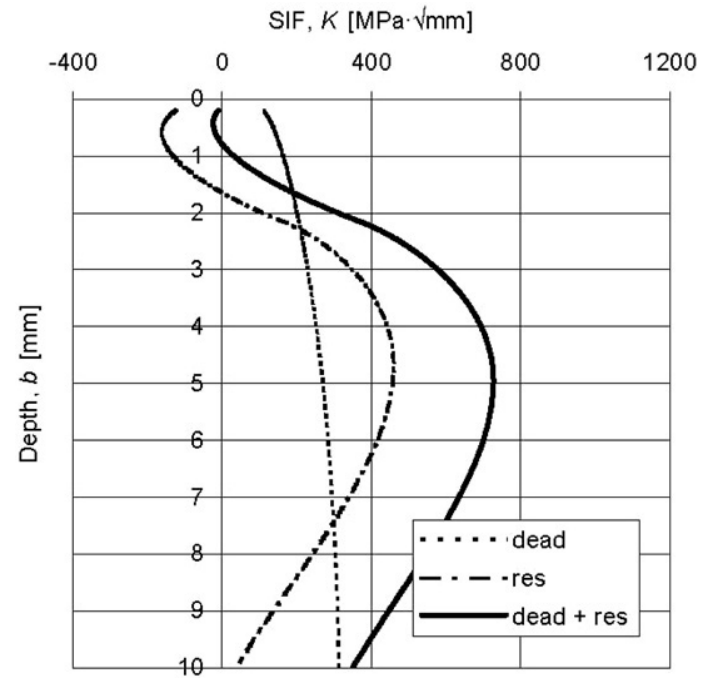

(b) Shop treated.

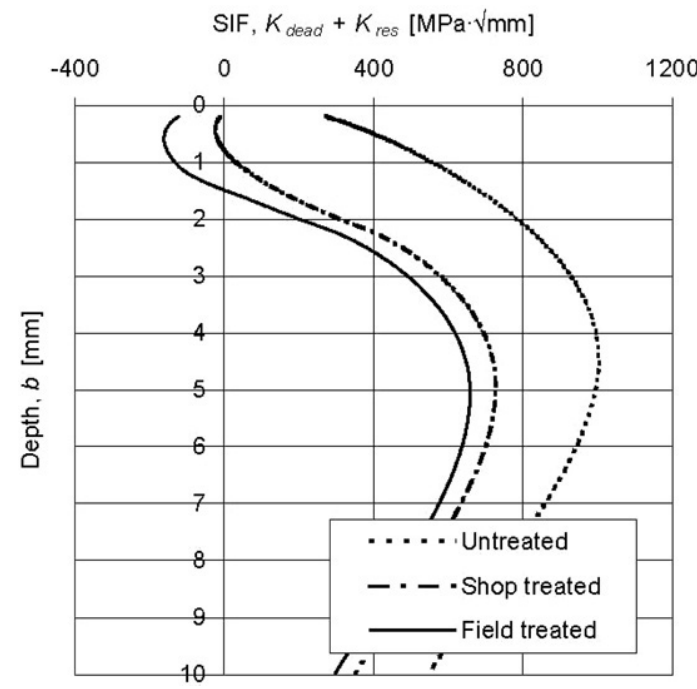

(d) $K_{\text {dead }}+K_{\text {res }}$ comparison (three cases).

Fig. 8. SIFs due to the dead load and residual stresses for three treatment cases.
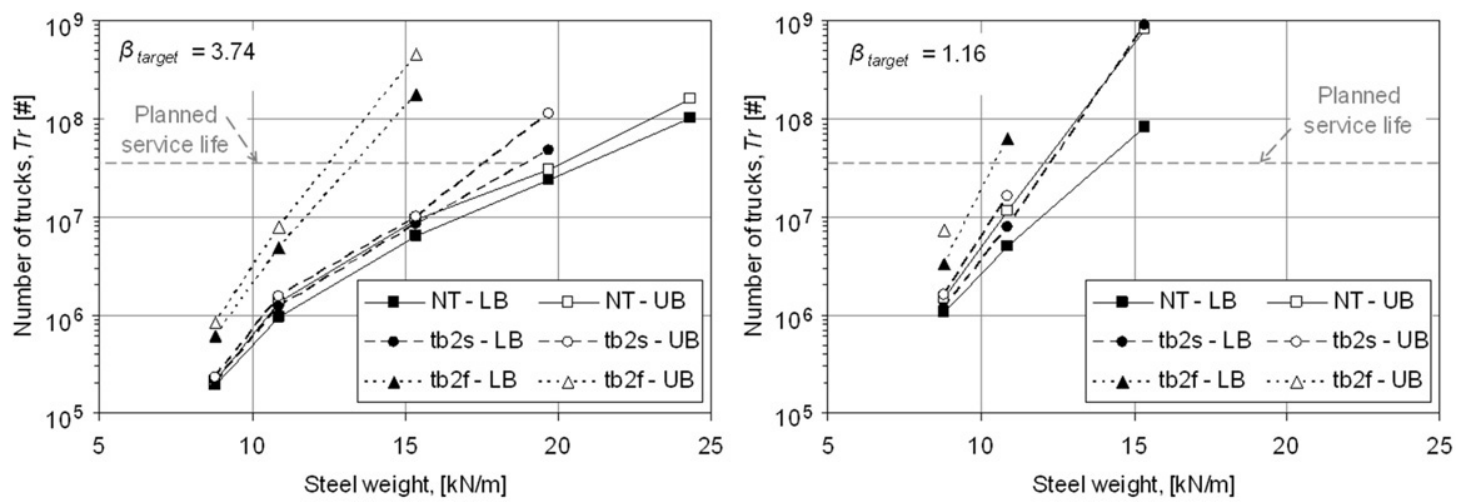

Note: $L B=$ lower bound reliability model (Eq. 7), UB = upper bound reliability model (Eq. 8).

Fig. 9. Fatigue life versus steel weight curves for shop and field treatment (TS4).

in steel weight due to post-weld treatment can be determined for any given target index at 70 years [8]. Again, looking at this figure, the additional benefit of field treatment (as opposed to shop treatment) is apparent. 


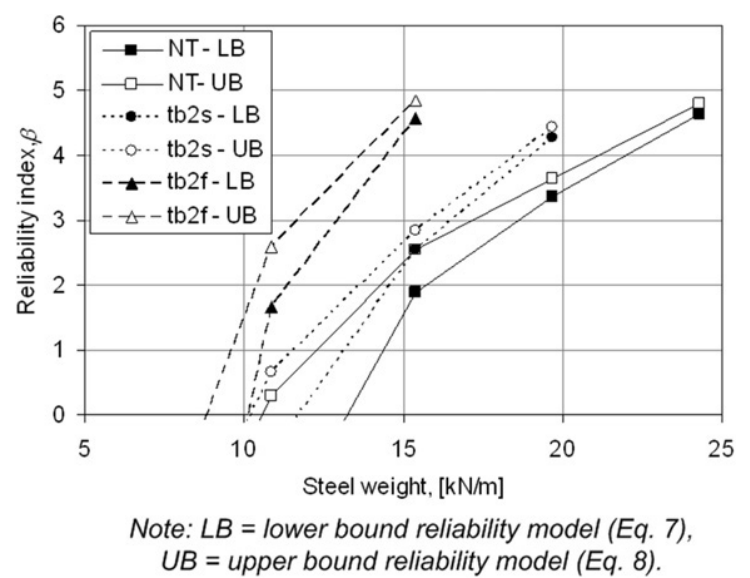

Fig. 10. Fatigue reliability versus steel weight curves for a 70 year planned service life (TS4).

\section{Consideration of phase effects and weld root cracking}

\subsection{Phase effects}

In the deterministic code-based fatigue verification described in Section 3, phase effects were ignored. In reality, the hot-spot stress peaks due to the five load cases in Fig. 4(a) will generally not be in-phase. Considering phase effects, i.e. by first calculating the hot-spot stress, $\sigma_{\mathrm{hs}}$, for each truck position using Eq. (12) and then determining the stress range using the resulting hot-spot stress influence line, was seen to improve the situation significantly, as seen in Fig. 11. In this figure results are presented of the deterministic fatigue verification for Bridge III considering phase effects (assuming $\gamma_{M f}=1.35$ ) for each hot-spot on each joint along the bottom chord of the interior span. An envelope of the results for the worst hot-spot on each joint brace member, obtained without considering phase effects, is included for comparison purposes. The design ratio, $D R$ or $\{D R\}_{\mathrm{PE}}$, in Fig. 11 is calculated as follows:

$$
\begin{aligned}
& D R=\frac{\text { resistance }}{\text { solicitation }}=\frac{\Delta \sigma_{c, t}}{\Delta \sigma_{E 2} \cdot \gamma_{M F}} \text { or } \\
& \{D R\}_{\mathrm{PE}}=\left\{\frac{\Delta \sigma_{c, t}}{\Delta \sigma_{E 2} \cdot \gamma_{M F}}\right\}_{\mathrm{PE}}
\end{aligned}
$$

where \{\}$_{\mathrm{PE}}$ indicates that phase effects are considered. Using this figure, it can be deduced that Bridge III could be made to pass the deterministic verification if phase effects are considered and a lower value for $\gamma_{M f}$ is permitted, such as 1.0. If the use of the higher $\gamma_{M f}$ value is deemed necessary, then Bridge III almost passes the verification if phase effects are considered, but fails by a considerable margin if they're ignored.

The results of the probabilistic calculations presented in Section 4 for single sites on the untreated bridge variants can be used to perform a verification of sorts of the deterministic, codebased design, as shown in Fig. 12(a). In this figure, the design ratio considering phase effects, $\{D R\}_{\mathrm{PE}}$, and assuming a low level of redundancy and limited possibility for inspection/repair $\left(\gamma_{M f}=1.35\right)$ is plotted verses the calculated fatigue life for the corresponding target reliability index, $\beta_{\text {target }}=3.74$. Looking at this figure, it can be concluded that according

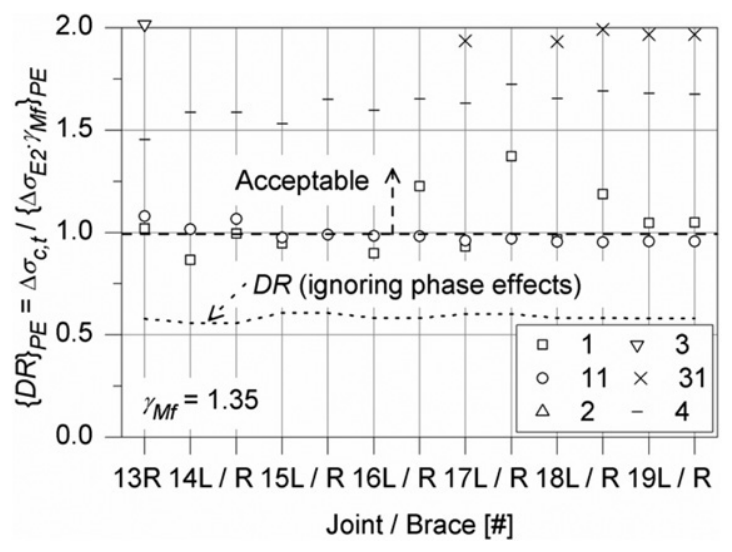

Fig. 11. Deterministic design ratios ignoring and considering phase effects.

to the probabilistic model, the code-based design gives safe results for single potential crack sites, even when phase effects are considered. In other words, there are virtually no cases where the code-based design deems a potential crack site to be adequate, while the probabilistic model shows it is not. Fig. 12(b) presents data for the case of $\gamma_{M f}=1.0 / \beta_{\text {target }}=$ 1.16, which follows a similar trend.

A number of the sites in Fig. 12(a) and (b) are seen to perform much better than would be expected simply by looking at the deterministic design ratio. The main reason for this is that the code-based verification does not consider the effects of compressive dead load stresses at the various potential crack sites. These stresses have a positive effect on the fatigue lives of these sites similar to that of the post-weld treatment stresses. This verification is also conservative in that the failure criterion for the probabilistic analysis is crack growth to a critical depth of $a_{c}=0.5 \cdot(T$ or $t)$. In fact, tubular structures are known to possess a significant reserve capacity beyond crack growth to this depth. According to [23], for example, the time to total joint failure is on average 1.49 times as long as the time to through thickness cracking. In addition, a constant, but conservative $D O B$ has been assumed for all of the load cases in Fig. 4(a).

One potentially unconservative assumption made by the probabilistic model is that the crack tip loading mode is essentially the same for all of the load cases in Fig. 4(a) (i.e. primarily opening or Mode I loading). It is thought that the error due to this assumption should be small, although further study of the effect of the true crack tip loading modes is recommended if phase effects are to be routinely considered in the code-based design. It was found in [24], for example, that out-of-phase loading can lead to a reduction in the fatigue lives of welded details subjected to pure normal and shear stress cycles that are completely out-of-phase. The various potential crack sites in tubular joints (in particular the critical sites on the joint saddle) are thought to experience primarily Mode I loading, however, suggesting that the consideration of phase effects should be less erroneous for these structures. Furthermore, most of the total fatigue life for these structures is spent in the crack propagation phase, where the implications of phase effects are less clear. The results presented herein do show, however, the potential of considering phase effects in the design of tubular truss bridges. Provided it can be confirmed to be safe, this 

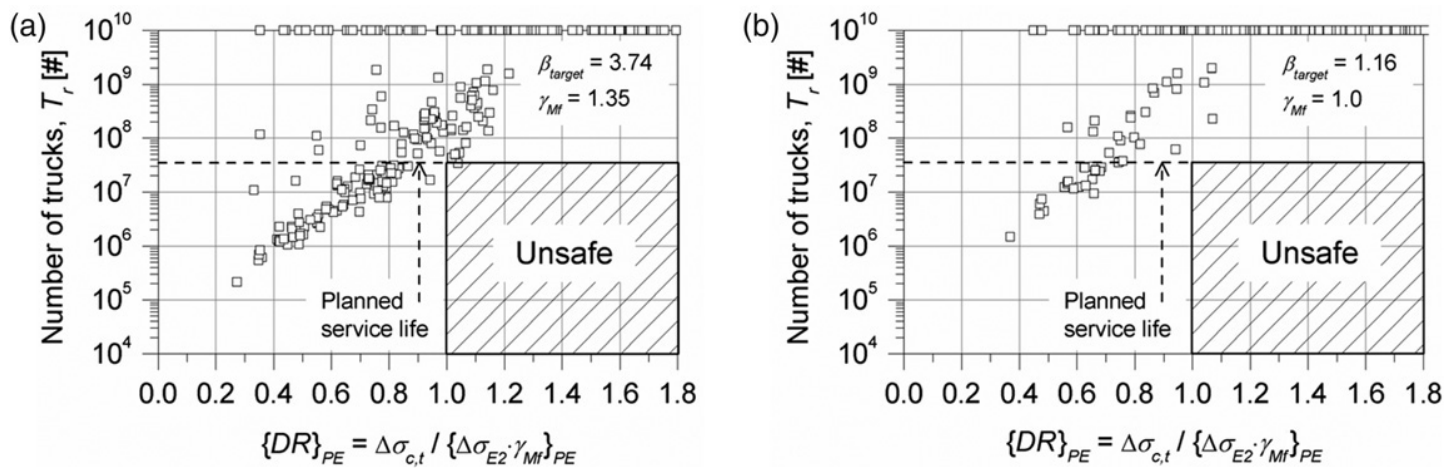

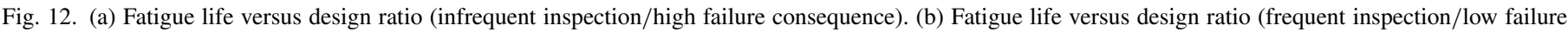
consequence).

design approach could lead to steel weight savings for these structures even greater than those that can be achieved by postweld treatment [8].

\subsection{Weld root cracking}

One potential concern with the use of post-weld treatment methods to improve fatigue performance is the increased possibility, with treatment, that the eventual failure of the joint will result from fatigue cracking at the weld root. Cracking at this location is generally considered to be much less desirable, as there is no economical possibility in this case for early detection using non-destructive methods. No suitable design tools currently exist for verifying the fatigue strengths of the weld roots in tubular bridge joints. One possible approach for offshore joints is discussed in [25]. This reference provides a set of equations for a factor, $R_{\mathrm{SCF}}$, which relates the maximum $\mathrm{SCF}$ at the weld root to that at the weld toe, i.e.:

$R_{\mathrm{SCF}}=\frac{\mathrm{SCF}_{\text {root, max }}}{\mathrm{SCF}_{\text {toe, max }}}$

Equations are provided in [25] for two of the brace load cases ( $a x \_b r$ and $\left.i p b 2 \_b r\right)$ in Fig. 4(a). Unfortunately, the validity range for the geometric parameter $\gamma(=0.5 \cdot D / T-$ see Fig. 2) is much higher $(12 \leq \gamma \leq 30)$ for these equations than the range for this parameter common to bridge structures. If these equations are extrapolated beyond this range, however, they can be applied to perform a preliminary, deterministic fatigue verification of the weld root for the investigated bridge. Example results are summarized in Fig. 13 for Bridge III.

In this figure, design ratios, $D R$, are plotted for each weld toe hot-spot, ignoring phase effects. Results are given for only six hot-spots per joint, since the left and right brace hot-spots have the same design stress ranges when phase effects are ignored. To generate a design stress range for the weld root, it was assumed that $R_{\mathrm{SCF}}$ was the same for both brace bending load cases in Fig. 4(a). It was also assumed that the chord load cases would not affect $R_{\mathrm{SCF}}$. Phase effects were ignored because it was necessary to separate the contributions of the various load cases to apply the equations from [25]. A conservative design hot-spot stress range of $90.6 \mathrm{MPa}$ at $2 \times 10^{6}$ cycles (HSE Class D) is suggested in [25] for the weld root regardless of $T$, based

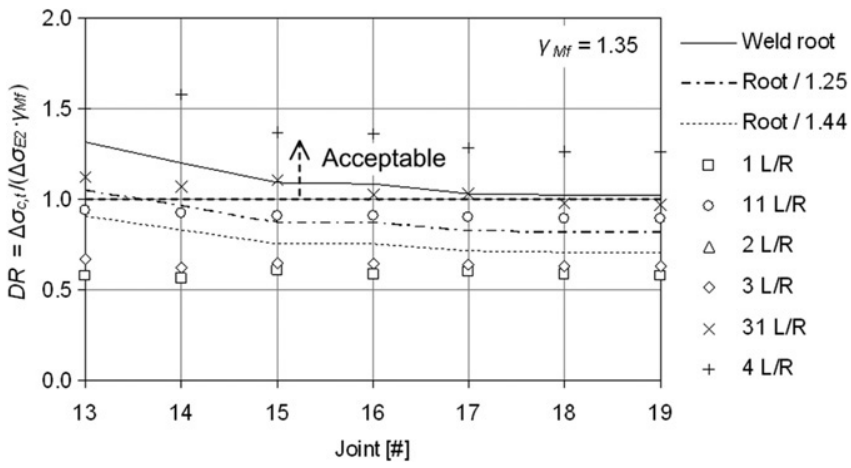

Fig. 13. Design ratios for various weld toe hot-spots and the weld root (ignoring phase effects).

on runout data for tubular joints with $T=16$ to $75 \mathrm{~mm}$. This range was determined using data that led to a detail category for the weld toe of $114 \mathrm{MPa}$ at $2 \times 10^{6}$ cycles (HSE Class $T^{\prime}$ ) for $T=16 \mathrm{~mm}$. With this in mind, the design hot-spot stress range for the weld root is taken herein as $72.3 \mathrm{MPa}$ at $2 \times 10^{6}$ cycles, regardless of $T$. This value was chosen to ensure a similar toeto-root fatigue strength ratio to that suggested in [25].

Looking at Fig. 13, it can be concluded that cracks will most likely always initiate from the weld toe in the untreated bridge. To make sure of this, it is often recommended that the weld root be designed with a fatigue life 100\%-200\% greater than that of the weld toe [25]. This can be equated to ensuring that the design ratio of the root is 1.25 to 1.44 times that of the toe if an $S-N$ curve slope of $m=3.0$ is assumed. Curves are plotted in Fig. 13 to reflect these two limits. Examining the resulting set of curves, it can be seen that there is still a significant potential to improve the fatigue performance of the weld toes for the various joints in this bridge, although there is an eventual limit to the allowable treatment benefit.

Further work is clearly needed to improve this verification for tubular bridge joints, specifically: to extend the equations in [25] to thick walled tubes $(\gamma<12)$, to determine the size effect (assuming there is one) for the weld root, and to modify the procedure to include phase effects. The importance of considering phase effects - in particular in the design of treated bridge joints - is highlighted in Fig. 13. The design ratios in this figure suggest that treating Sites 1 and 3 only would be a good partial treatment strategy, whereas Sites 1 and 
11 are always found to be the most critical when phase effects are considered (see Fig. 11).

\section{Conclusions}

The probabilistic analysis results presented herein demonstrate that the use of residual stress-based post-weld treatment methods such as needle peening can result in significant benefits for tubular truss bridges. Specifically, it is shown that postweld treatment by normal intensity/uniformity needle peening in the shop can result in a $120 \%$ to $930 \%$ increase in fatigue life, depending on whether a lower or an upper bound series system reliability model is used, as well as on the selected target reliability index.

In examining the analytical results for the various potential crack sites in the five studied bridge variants, the mean applied stress level is seen to strongly influence the treatment benefit for the various potential crack sites in a typical tubular truss bridge. On this basis, the possibility of post-weld treatment in the field (i.e. after the dead load stresses are introduced) is suggested. In comparing the benefits of shop versus field treatment, it is observed that residual stress-based post-weld treatment methods can be much more effective if the latter approach is employed. This finding suggests that an interesting domain of application for these methods might be in the rehabilitation or fatigue life extension of existing steel bridges.

The results of the probabilistic analysis presented herein are also used to examine the implications of ignoring or considering phase effects in the design of tubular truss bridges. This examination shows that the potential benefit of considering phase effects is significant. Further work is needed, however, to confirm that the assumption of Mode 1 crack loading for all nominal load cases will not lead to unsafe designs. Finally, a preliminary, deterministic verification of the weld root is presented. Although this verification shows that partial treatment of these bridge joints will likely not cause the critical crack location to shift to the weld root, further work is needed to develop parametric equations for the $R_{\mathrm{SCF}}$ factor that are more suitable for tubular bridge applications. In addition, there would be considerable value in modifying the weld root verification procedure so that phase effects can be considered.

\section{Acknowledgements}

The work presented herein was supported by the Swiss Federal Highway Administration (OFROU Project No. AGB2002/011) and the Swiss National Research Foundation (SNF Grant 200020-101521).

\section{References}

[1] Virlogeux M, Bouchon E, Berthellemy J, Resplendino J. The antrenas tubular arch bridge. Structural Engineering International 1997;97(2):1-7109.

[2] Dauner H-G, Decorges G, Oribasi A, Wéry D. The Lully Viaduct, a composite bridge with steel tube truss. Journal of Constructional Steel Research 1998;46(1-3). Paper No. 55.
[3] Manterola ArmisénJ, Gil Ginés M-A, Martínez CutillasA. Bridge over the Llobregat river (Barcelona, Spain) and bridge over the Escudo river (Cantabria, Spain). In: Jaurrieta MA, Alonso A, Chica JA, editors. Tubular structures X, 2003. Madrid: A.A. Balkema; 2003.

[4] Schumacher A, Nussbaumer A. Experimental study on the fatigue behaviour of welded tubular $K$-joints for bridges. Engineering Structures 2006;28(5):745-55.

[5] Veselcic M, Herion S, Puthli R. Cast steel in tubular bridges-new applications and technologies. In: Jaurrieta MA, Alonso A, Chica JA, editors. Tubular structures X, 2003. Madrid: A.A. Balkema; 2003.

[6] Haldimann-Sturm S, Nussbaumer A. Determination of allowable defects in cast steel nodes for tubular bridge applications. International Journal of Fatigue [in press].

[7] Manteghi S, Maddox SJ. Methods for fatigue life improvement of welded joints in medium and high strength steels. International Institute of Welding Doc. XIII-2006-04. 2004.

[8] Walbridge S. A probabilistic study of fatigue in post-weld treated tubular bridge structures. EPFL thesis no. 3330. Lausanne, http://icom.epfl.ch; 2005.

[9] Walbridge S, Nussbaumer A. A probabilistic model for determining the effect of post-weld treatment on the fatigue performance of tubular bridge joints. International Journal of Fatigue 2007;29:516-32.

[10] Bremen U. Amelioration du comportement à la fatigue d'assemblages soudés: étude et modélisation de l'effet de contraintes residuelles. EPFL thesis no. 787. Lausanne; 1989.

[11] Stephens RI, Fatemi A, Stephens RR, Fuchs HO. Metal fatigue in engineering. 2nd ed. New York: John Wiley \& Sons; 2001.

[12] Stacey A, Barthelemy J-Y, Leggatt RH, Ainsworth RA. Incorporation of residual stresses into the SINTAP defect assessment procedure. Engineering Fracture Mechanics 2000;67:573-611.

[13] Porter Goff RFD, Free JA, Tsiagbe WZ. Experimental determination of residual stresses in welded tubular T-joints. Fatigue of Offshore Structures 1988;285-95.

[14] Albrecht P, Yamada K. Rapid calculation of stress intensity factors. Journal of Structural Engineering 1977;103(ST2):377-89.

[15] Bowness D, Lee MMK. Weld toe magnification factors for semi-elliptical cracks in T-butt joints. Health and safety executive offshore technology report OTO 199 014. UK; 1999.

[16] Newman JC, Raju IS. An empirical stress-intensity factor equation for the surface crack. Engineering Fracture Mechanics 1981;15(1-2):185-92.

[17] Connolly MP, Hellier AK, Dover WD, Sutomo J. A parametric study of the ratio of bending to membrane stress in tubular Y- and T-joints. International Journal of Fatigue 1990;1:3-11.

[18] Melchers RE. Structural reliability analysis and prediction. 2nd ed. Chichester: John Wiley \& Sons; 1999.

[19] SIA 260/261/263-Basis for structural design/actions on structures/steel structures. Zurich: Swiss Society of Engineers and Architects; 2003.

[20] EN1990-Basis of structural design. Brussels: European Committee for Standardization; 2002.

[21] Zhao XL, Herion S, Packer JA, et al. Guide no. 8-Design guide for circular and rectangular hollow section joints under fatigue loading. Cologne: CIDECT; 2001.

[22] Kunz P, Hirt MA. Grundlagen und Annahmen für den Nachweis der Ermüdungsfestigkeit in den Tragwerksnormen des SIA. Zurich: Swiss Society of Engineers and Architects Doc. D 076; 1991.

[23] van Wingerde AM, van Delft DRV, Wardenier J, Packer JA. Scale effects on the fatigue behaviour of tubular structures. International Institute of Welding WRC Proceedings; 1997.

[24] Sonsino CM. Multiaxial fatigue of welded joints under in-phase and outof-phase local strains and stresses. International Journal of Fatigue 1995; 17(1):55-70.

[25] Fatigue life implications for design and inspection for single sided welds at tubular joints. Health and Safety Executive offshore technology report OTO 99/022. UK; 1999. 